\title{
Simulation of the global bio-geophysical interactions during the Last Glacial Maximum
}

\author{
Claudia Kubatzki, Martin Claussen \\ Potsdam-Institut für Klimafolgenforschung \\ Postfach 601203, D-14412 Potsdam
}

\author{
correspondence to: \\ Claudia Kubatzki \\ email: kubi@pik-potsdam.de \\ fax: $+49(0) 3312781204$
}




\begin{abstract}
The bio-geophysical feedbacks during the Last Glacial Maximum (LGM, 21,000 yBP) are investigated by use of an asynchronously coupled global atmosphere-biome model. It is found that the coupled model improves on the results of an atmosphere-only model, especially for the Siberian region, where the inclusion of vegetation-snow-albedo interaction leads to a better agreement with geological reconstructions. Furthermore, it is shown that two stable solutions of the coupled model are possible under LGM boundary conditions. The presence of bright sand desert at the beginning of a simulation leads to more extensive subtropical deserts, whereas an initial global vegetation cover with forest, steppe, or dark desert results in a northward spread of vegetation of up to some $1,000 \mathrm{~km}$, mainly in the western Sahara. These differences can be explained in the framework of Charney's (1975) theory of a self-induction of deserts through albedo enhancement. Moreover, it is seen that the tropical easterly jet is strengthened in the case of the "green" Sahara, which in turn leads to a modification of the Indian summer monsoon.
\end{abstract}




\section{Introduction}

It has been amply documented that vegetation plays an important role in the climate system (e.g. Dickinson et al. 1986, Sellers et al. 1986). Recent theoretical studies indicate that atmosphere-vegetation feedbacks were even capable of amplifying orbitally induced climate changes that occurred during the last 120,000 years, the late Pleistocene and early Holocene (e.g. de Noblet et al. 1996, Foley et al. 1994, Gallimore and Kutzbach 1996, Kutzbach et al. 1996, Claussen and Gayler 1997). For the Late Cretaceous period (some 66 million years ago), Otto-Bliesner and Upchurch (1997) find from their simulations that high latitude forest vegetation warms the global climate by $2.2^{\circ} \mathrm{C}$. Moreover, Dutton and Barron (1996) show in their numerical experiments for the Miocene (23 to 5.3 million years ago) that our inability to use the geologic record for specification of the global vegetation distribution may introduce errors of as much as $\pm 1{ }^{\circ} \mathrm{C}$ in globally averaged surface temperature predictions. Therefore, investigation of the atmosphere-vegetation feedback is interesting in two respects. Firstly, coupled atmosphere-biosphere models are capable of simulating their own land-surface characteristics for different times of the Earth's history. In this way, they do not have to rely on reconstructions from often sparse and uncertain geological information. Secondly, the role of the atmosphere-vegetation feedback within the climate system tends to depend on the external boundary conditions, such as orbital parameters, atmospheric composition, land-sea distribution, and land elevation. Hence a prerequisite for understanding the dynamics of the climate system is the study of these feedbacks during various periods of the Earth's history. Here, we will focus our attention on the biogeophysical feedbacks during the Last Glacial Maximum (LGM) some 21,000 years ago.

Within the framework of the Paleoclimate Modelling Intercomparison Project (PMIP) Lorenz et al. (1997) performed - among others - a simulation of the LGM with the Hamburg general circulation model ECHAM. The land-surface parameters prescribed for this simulation essentially represent present-day conditions. The equilibrium biome distribution (determined by use of the BIOME model of Prentice et al. 1992) corresponding to the simulated LGM climate reveals differences from geological reconstructions (Crowley 1995, Frenzel 1992, Grichuk 1992, Velichko and Isayeva 1992), especially in the boreal regions south of the Eurasian ice sheet where the expansion of forest is overestimated by the model. We hope that coupling the atmospheric model ECHAM with the BIOME model will lead to a better representation of the glacial vegetation pattern. At least, this method has proved to be rather successful in the simulation of the climate of the so-called Holocene Optimum, 6,000 years before present (e.g. Claussen 
and Gayler 1997).

Concerning the dynamics of the biogeophysical feedback it has been found that the ECHAM-BIOME model can be transitive or intransitive. Studies of Claussen (1994), Claussen (1997a), Claussen (1997b) reveal that two different equilibrium states of ECHAM-BIOME are possible under present-day conditions of solar irradiation and sea-surface temperatures (SSTs). The most striking differences appear in the western Sahara where either vegetation or desert are observed, depending on the initial biome distribution. This is explained in terms of Charney's (1975) theory of a self-induction of deserts through albedo inhancement. Similar studies of Claussen and Gayler (1997) for the Holocene Optimum show only one stable solution of the coupled model. Independent of the initial land-surface conditions, a vegetated western Sahara is observed, in qualitative agreement with geological reconstructions. Hence it is interesting to explore the manifold of equilibrium solutions of ECHAM-BIOME under LGM boundary conditions.

\section{The models}

\subsection{The atmospheric model}

The ECHAM general circulation model was initially developed at the European Centre for Medium Range Weather Forecasts in Reading and was later modified at the MaxPlanck-Institut für Meteorologie in Hamburg. A detailed description of the model and of its validation can be found in Roeckner et al. (1992).

Here, ECHAM (level 3) is run at T42 resolution, which corresponds to a Gaussian grid of $128 \times 64$ points with a spatial resolution of about 2.8 degrees in longitude and latitude. The vertical plane is divided into 19 layers: Sigma layers near the ground pass into pressure isosurfaces with the last one being at $10 \mathrm{hPa}$. The time step is 24 minutes.

For the simulation of the LGM (21,000 years before present), the orbital parameters (eccentricity, obliquity, and day of perihelion) had to be adapted. These values are calculated following Berger (1978). As described by PMIP the date of the vernal equinox is set to March 21 (12.00 GMT). The solar constant is set to $1365 \mathrm{~W} / \mathrm{m}^{2}$. The obtained insolation differences are small in comparison with present-day values and reach values of up to $-10 \mathrm{~W} / \mathrm{m}^{2}$ at the respective summer pole. It should be mentionned that according to Joussaume and Braçonnot (1995) the definition of the calendar should be based on the position of the earth with respect to the vernal equinox. In this way changes in the length of the seasons (e.g. Berger and Loutre 1994) caused by 
precession and by changes in eccentricity can be taken into account. Our model results presented in the following chapter are calculated using the present-day calendar. As this is the classical procedure in climate simulations the comparison of our results with results of other model simulations is justified, provided all simulations use the same reference date which is usually the case. As only averages over summer and winter seasons are discussed for all our experiments and as changes in the length of the season are small for LGM the results themselves appear not much biased.

In addition, SSTs, sea-ice distribution, ice sheets, orography, land-sea distribution, and $\mathrm{CO}_{2}$ concentration had to be adjusted (cf. Lorenz et al. 1997). These values are taken from CLIMAP data (Climate Long-Range Investigation, Mapping, and Prediction; CLIMAP Members 1981), except for the thickness of ice sheets which is prescribed according to more recent estimates by Tushingham and Peltier (1991). The atmospheric $\mathrm{CO}_{2}$ concentration of $200 \mathrm{ppmv}$ is based on findings from the Vostok ice core (Barnola et al. 1987). The accuracy of the SSTs as given by CLIMAP is widely discussed (e.g. Webb et al. 1997). Especially the stated surface temperature decrease for the tropical ocean of $1-2^{\circ} \mathrm{C}$ is supposed to be too small and doesn't agree with an estimated cooling of about $5^{\circ} \mathrm{C}$ for the tropical land areas (Crowley and North 1990, Jolly et al. 1996). A recent LGM simulation with a coupled 2.5-dimensional atmosphere-ocean model indicates the cooling in SST between $20^{\circ} \mathrm{S}$ and $20^{\circ} \mathrm{N}$ to reach values of up to $3.3^{\circ} \mathrm{C}$ which is consistent with the land data as well as with more recent estimates of ocean surface temperatures (Ganopolski et al. 1997).

There are several surface parameters in ECHAM3 controlling energy, momentum, and moisture fluxes - i.e. background albedo, leaf area index, vegetation ratio, forest ratio, and roughness length of vegetation. The hydrological cycle for instance is described in terms of three reservoirs. Soil moisture depends on transpiration, among other factors. This variable in turn is influenced e.g. by leaf area index and photosynthetically active radiation which together with a moisture-dependent water stress factor describe the stomatal resistance. Changes in the interception reservoir are calculated as a function of the evaporation of intercepted water and of the vegetation ratio. The maximum skin water content also depends on the vegetation ratio and the leaf area index. The forest ratio influences the radiation balance via the albedo of snow. The background albedo of snowfree land is prescribed according to satellite data. The roughness length of vegetation enters into the calculation of turbulent fluxes.

In the original version of ECHAM3 these surface parameters are assumed to be timeindependent or are even taken as global constants. For the PMIP simulation of the LGM, present-day values of these parameters are prescribed and are extrapolated to 
land areas which emerged during the LGM owing to the lower sea level. For the coupling with a biome model the parameters are allowed to vary with changing ground cover (see section 2.3).

In contrast to the new version 4 of the model (Roeckner et al. 1996), ECHAM3 assumes all soil characteristics including the water holding capacity to be the same over all continents. On the other hand, in the version of the biome model used here, soil properties can only be considered in terms of total available water capacity. Specifying these values especially for paleosimulations is still a problem. A detailed description of sensitivity studies concerning soil-vegetation feedback in the ECHAM4-BIOME system can be found in Stahmann (1996). They show the total available water capacity to be the dominant characteristic, especially in the tropics. Modified water capacity do not influence the existence of two equilibrium states under present-day conditions as described in the introduction.

\subsection{The biome model}

The BIOME model (version 1.0) of Prentice et al. (1992) determines the potential biome distribution, i.e. the distribution of macro ecosystems that is in equilibrium with a given atmospheric state. Migration processes and succession as well as e.g. extreme events or effects of $\mathrm{CO}_{2}$ are not taken into account.

Monthly mean values of near-surface temperature, precipitation, and cloud cover are used to calculate the values of five bioclimatic variables at each grid point: mean temperatures of the warmest and of the coldest month of the year, temperature sums $\left(\mathrm{GDD}_{T_{0}}=\int\left(\mathrm{T}-\mathrm{T}_{0}\right) \mathrm{dt}\right.$ with $\mathrm{T} \geq \mathrm{T}_{0}$ and $\mathrm{T}_{0}=0^{\circ} \mathrm{C}$ resp. $\left.5^{\circ} \mathrm{C}\right)$, and an annual moisture availability index (the ratio of estimated actual to equilibrium evapotranspiration).

Physiologically based minimum and maximum tolerances of these bioclimatic variables determine which of 14 plant functional types - i.e. plant types with similar environmental demands - can exist under the given climatic conditions. Finally, 17 biomes result as combinations of plant types that are dominant according to a dominance hierarchy, which - in a simplified way - takes into account the competition between different types.

\subsection{Coupling the atmospheric model with the biome model}

In this study, ECHAM and BIOME are coupled in an asynchronous way. Firstly, a given set of climate variables calculated by ECHAM is used for the determination of the corresponding biomes, as described in the previous section. Secondly, a set of surface 


\begin{tabular}{|rl||c|c|c|c|c|}
\hline \multicolumn{2}{|c||}{ biome } & $\alpha_{V}$ & LAI & $\mathrm{C}_{V}$ & $\mathrm{C}_{F}$ & $\mathrm{z}_{\text {oveg }}$ \\
\hline \hline 1 & tropical rain forest & 0,15 & 9,30 & 0,98 & 0,98 & 2,000 \\
2 & tropical seasonal forest & 0,15 & 6,00 & 0,91 & 0,82 & 2,000 \\
3 & savanna & 0,15 & 3,59 & 0,76 & 0,58 & 0,360 \\
4 & warm mixed forest & 0,15 & 7,62 & 0,95 & 0,79 & 0,716 \\
5 & temperate deciduous forest & 0,16 & 5,20 & 0,88 & 0,65 & 1,000 \\
6 & cool mixed forest & 0,15 & 3,80 & 0,78 & 0,54 & 1,000 \\
7 & cool conifer forest & 0,15 & 9,20 & 0,97 & 0,97 & 1,000 \\
8 & taiga & 0,15 & 4,80 & 0,85 & 0,77 & 0,634 \\
9 & cold mixed forest & 0,15 & 3,80 & 0,78 & 0,54 & 1,000 \\
10 & cold deciduous forest & 0,15 & 4,80 & 0,85 & 0,77 & 0,634 \\
11 & xerophytic woods/shrub & 0,18 & 4,33 & 0,82 & 0,19 & 0,111 \\
12 & warm grass/shrub & 0,20 & 1,50 & 0,45 & 0,00 & 0,100 \\
13 & cool grass/shrub & 0,19 & 1,98 & 0,55 & 0,00 & 0,055 \\
14 & tundra & 0,17 & 2,24 & 0,59 & 0,06 & 0,033 \\
15 & hot desert & 0,20 & 0,45 & 0,16 & 0,00 & 0,004 \\
16 & cool desert & 0,20 & 0,50 & 0,18 & 0,00 & 0,005 \\
17 & ice/polar desert & 0,17 & 0,00 & 0,00 & 0,00 & 0,001 \\
18 & sand desert & 0,00 & 0,00 & 0,00 & 0,004 \\
\hline
\end{tabular}

Table 1: Allocation of surface parameters used in the atmosphere model ECHAM to biomes specified in BIOME: background albedo $\left(\alpha_{V}\right)$, leaf area index (LAI), vegetation ratio $\left(\mathrm{C}_{V}\right)$, forest ratio $\left(\mathrm{C}_{F}\right)$, and roughness length of vegetation $\left(\mathrm{z}_{0 \text { veg }}[\mathrm{m}]\right)$ (after Claussen 1997a).

parameters is allocated to each biome (see table 1). Thirdly, the subsequent integration with ECHAM is performed with the updated global set of surface parameters. Following Claussen (1994), the first year of each ECHAM integration is taken as adjustment time. To exclude interannual variability average values over the subsequent five years are again used for the determination of biomes and so on. In the following, each of these cycles is called an iteration.

BIOME-1.0 is not intended to simulate the dynamical behaviour of the biosphere. Therefore, the coupled ECHAM-BIOME model yields only steady-state equilibrium solutions of the vegetation-atmosphere system. Hence we implicitly assume the vegetation during the LGM to be in equilibrium with climate.

The original version of BIOME includes 17 biomes which - as described - can be distinguished for biological reasons. Here, an additional land surface type - sand desert is introduced to take into account extremely high albedo values in the interior of the 
Sahara and the Arabian penninsula (Claussen 1997a). As a clear allocation of sand desert to climate and soil characteristics was not possible the distinction between this new surface type and hot desert is based on satellite data. Wherever BIOME determines hot desert whereas satellite data indicate an albedo of more than $30 \%$, hot desert is replaced by sand desert. Implicit in the specification of sand desert is the assumption that the evolution of soils takes place at much longer time scales than a few 10,000 years.

\section{Experiments and Results}

\subsection{The coupled ECHAM-BIOME model}

\subsubsection{The experiment}

To minimize spin-up, the simulation with the coupled ECHAM-BIOME model (in the following called CONTROL) has been initialized with the last restart files of the PMIP simulation with the (uncoupled) ECHAM model (in the following called PLGM). The initial values of the surface parameters in CONTROL are diagnosed from the global biome distribution corresponding to mean climatic conditions of the last ten years of PLGM.

Six iterations have been performed. Since the last five iterations of CONTROL reveal no temporal trends in the land areal coverage of each biome, this period is taken as equilibrium time. In addition, the global $\kappa$ values show no trends within this period when comparing biome distributions of successive iterations or of individual iterations with the equilibrium distribution of PLGM (The $\kappa$ value is used as a measure of agreement of two vegetation maps. It is based on the calculation of a matrix whose elements $\mathrm{p}_{i j}$ give the fraction of the land area of those grid boxes that are covered by biome $\mathrm{i}$ in the one and biome $\mathrm{j}$ in the other map. The sum of the values on the main diagonal shows the degree of agreement of the two maps. Consideration of accidental agreement leads to the definition of global $\kappa$ which reaches values of 1 for identical maps; see Monserud and Leemans 1992.).

Biome maps (see fig. 1) and values of climate variables discussed in the following represent these equilibrium conditions.

\subsubsection{Results}

The most striking climatic differences between the uncoupled and the coupled simulation can be observed in the northern hemisphere. Above all, a large part of Eurasia 

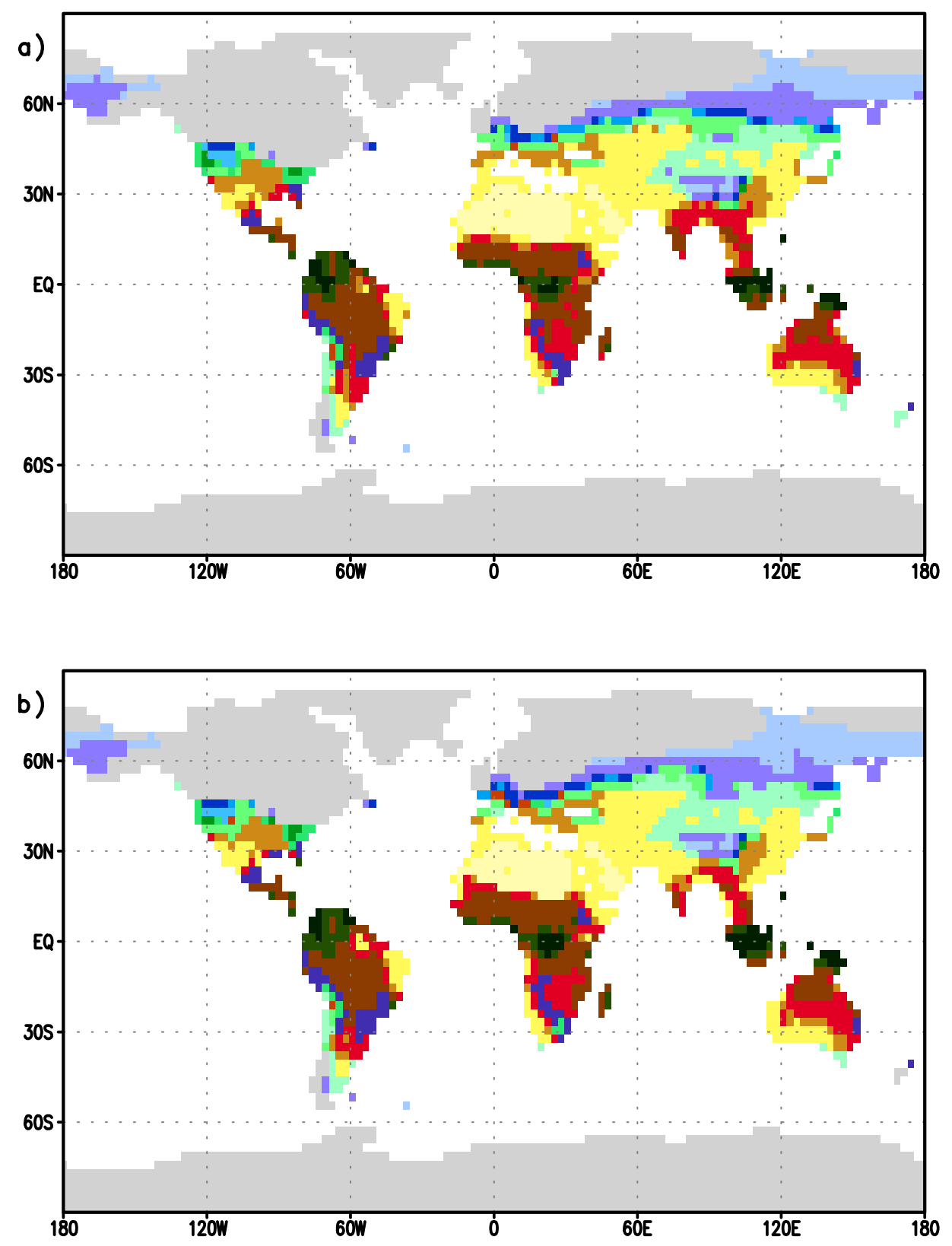

tropical rain forest tropical seasonal forest sovanno

warm mixed forest temperate deciduous forest cool mixed forest cool conifer forest taiga cold mixed forest cold deciduous forest xerophytic woods/shrub warm grass/shrub cool grass/shrub tundra hot desert cool desert ice/polar desert sand desert ice sheets

Figure 1: a) Equilibrium biome distribution of the LGM simulation PLGM with the atmosphere-only model ECHAM. b) Same as Figure a), but for the simulation CONTROL with the coupled ECHAM-BIOME model. Note the southward expansion of polar desert and tundra in Siberia. 


\begin{tabular}{|l||c|c||c|c|}
\hline \multicolumn{1}{|c||}{} & \multicolumn{2}{c||}{ East Asia } & \multicolumn{2}{c|}{ Central Asia } \\
\multicolumn{1}{|l||}{ climate variable } & $\left(34-68^{\circ} \mathrm{N} / 108-145^{\circ} \mathrm{E}\right)$ & $\left(28-62^{\circ} \mathrm{N} / 58-108^{\circ} \mathrm{E}\right)$ \\
\cline { 2 - 5 } & PLGM & CONTROL & PLGM & CONTROL \\
\hline \hline forest ratio [\%] & 53 & 4 & 24 & 4 \\
surface albedo $[\%]$ & 16 & 22 & 18 & 20 \\
\hline shortwave radiation $\uparrow\left[\frac{W}{m^{2}}\right]$ & -39 & -54 & -55 & -61 \\
net shortwave radiation $\left[\frac{W}{m^{2}}\right]$ & 213 & 202 & 253 & 247 \\
\hline thermal radiation $\uparrow\left[\frac{W}{m^{2}}\right]$ & -396 & -383 & -402 & -394 \\
atmospheric radiation $\left[\frac{W}{m^{2}}\right]$ & 308 & 298 & 277 & 271 \\
net thermal radiation $\left[\frac{W}{m^{2}}\right]$ & -88 & -85 & -125 & -122 \\
\hline net radiation $\left[\frac{W}{m^{2}}\right]$ & 125 & 117 & 127 & 125 \\
\hline $2 m-$ temperature $\left[{ }^{\circ} \mathrm{C}\right]$ & 14.9 & 12.6 & 16.1 & 14.5 \\
\hline \hline taiga and cold dec. forest $[$ frac] & 7.2 & 3.0 & 5.6 & 3.0 \\
tundra and ice/polar desert $[\mathrm{frac}]$ & 33.1 & 39.5 & 20.7 & 27.8 \\
\hline
\end{tabular}

Table 2: Mean values of various surface parameters and climate variables of the LGM simulations with the atmosphere-only model ECHAM (PLGM) and with the coupled ECHAM-BIOME model (CONTROL) in the regions East and Central Asia (JJA); negative values indicate upward fluxes. Except for the net thermal radiation in East Asia, all differences CONTROL-PLGM are significant at a $1 \%$ level.

appears colder in CONTROL than in PLGM by some $1-2^{\circ} \mathrm{C}$ (see fig. 2a/b). The strongest cooling of more than $5^{\circ} \mathrm{C}$ is found in the Siberian region.

How can this be explained? In PLGM, the surface parameters are held at constant values corresponding to present-day conditions (cf. table 2). In the north of Eastern and Central Asia, these values represent large areas of forest (cf. fig. 3). In CONTROL, the vegetation can adjust to the simulated climatic conditions which leads to more widespread polar desert and tundra in this region.

The albedo of polar desert and of snow-covered tundra is higher than that of snowcovered forest. For this reason, more solar radiation is reflected in CONTROL than in PLGM. As changes in net thermal radiation are only small, the resulting lower temperatures in CONTROL in turn inhibit forest growth. The vegetation-snow-albedo feedback has been amply investigated (Harvey 1988, Bonan et al. 1992, Chalita and LeTreut 1994, Foley et al. 1994). It even turned out to be an important factor in the process of glaciation and deglaciation (Gallée et al 1992, de Noblet et al. 1996, Gallimore and Kutzbach 1996).

The reduction of forest and the southward expansion of tundra in the coupled ECHAM- 


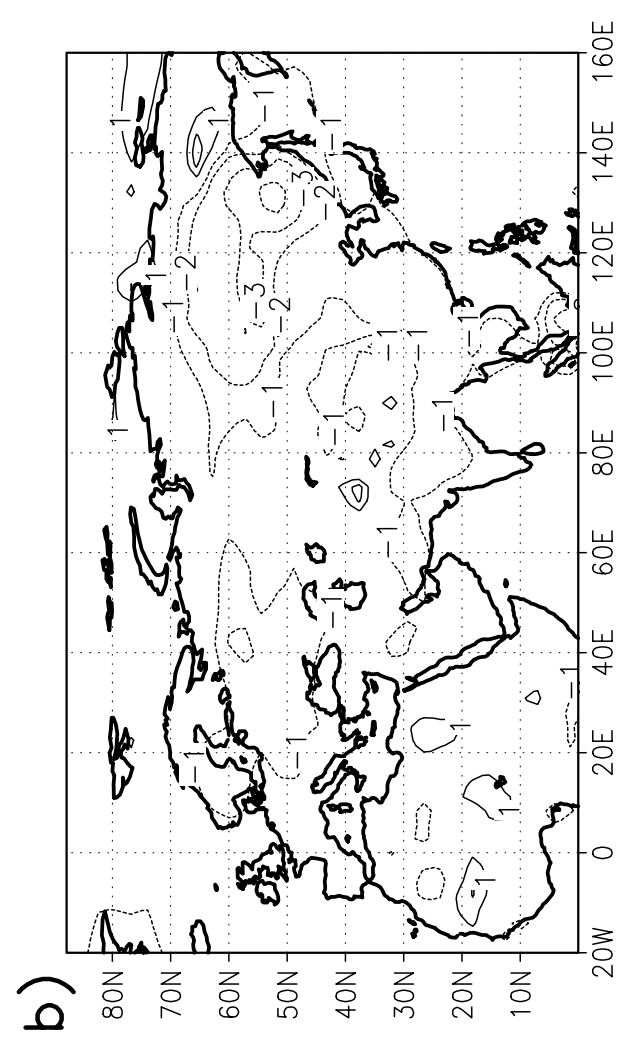

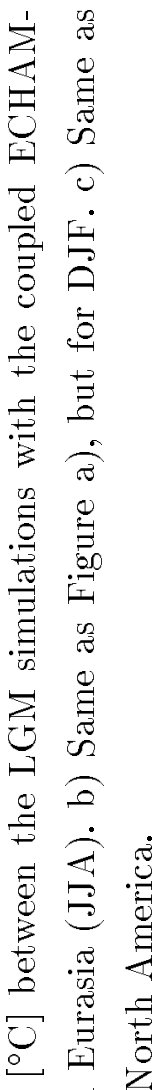

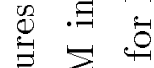
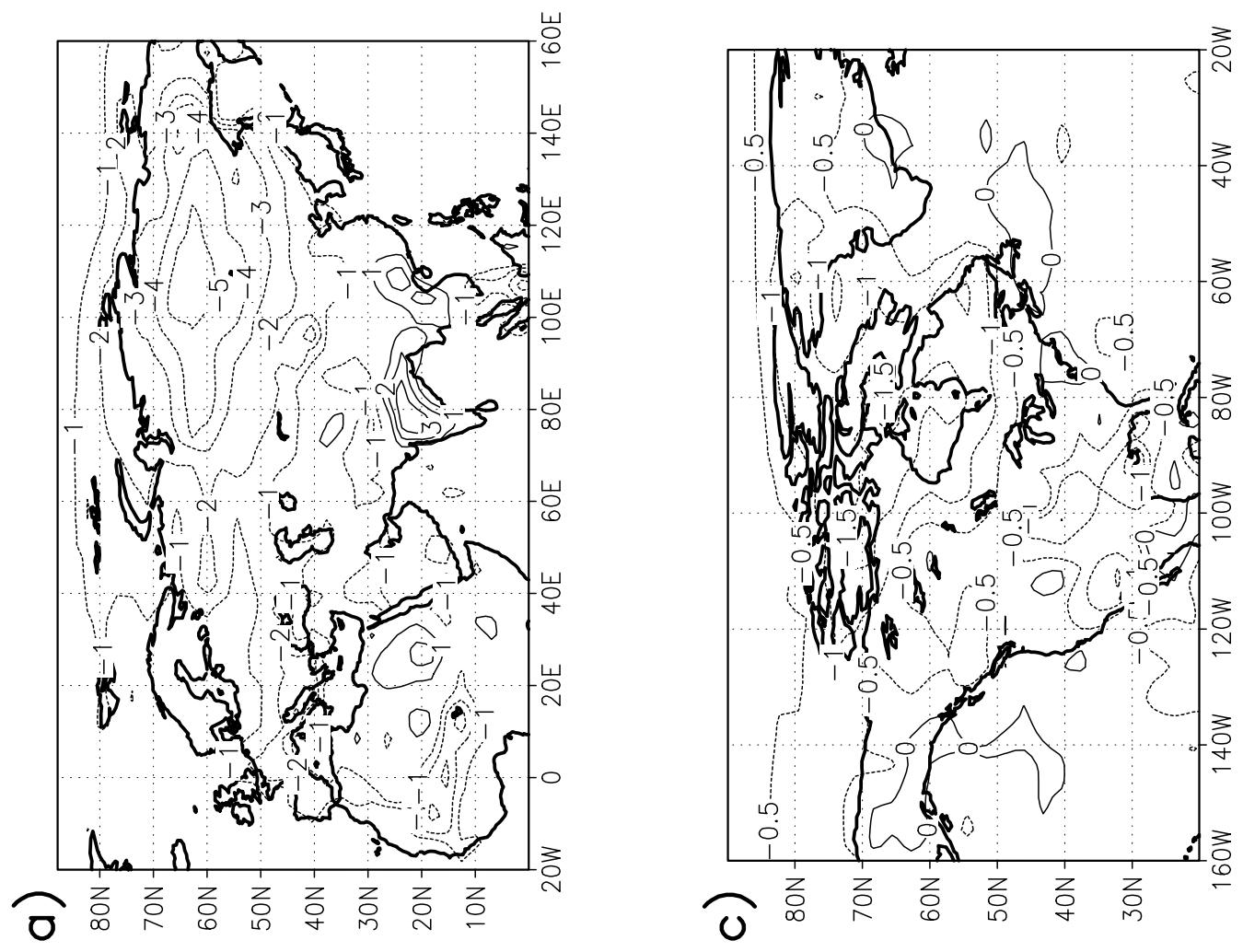

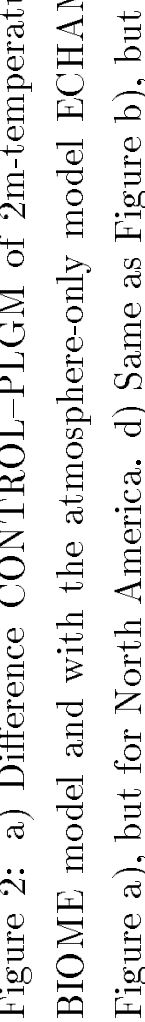




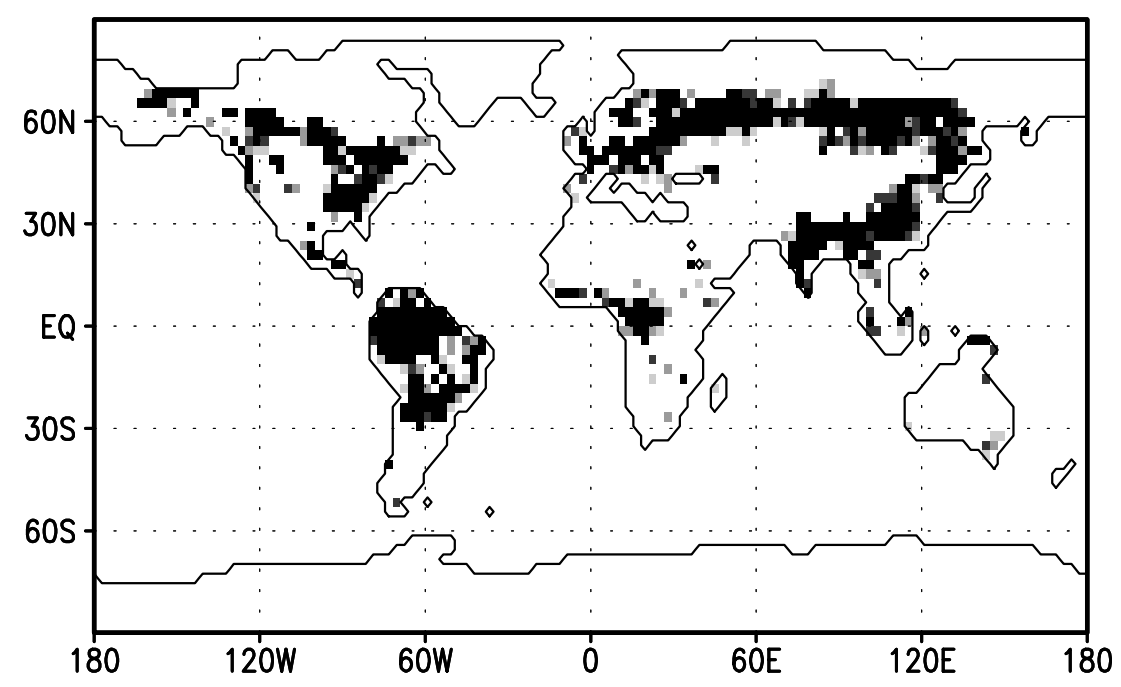

Figure 3: Forest ratio prescribed in the LGM simulation PLGM with the atmosphereonly model ECHAM. Shaded grid boxes indicate values between 0.2 and 1.0 (interval 0.2 ). Note the unrealistically high values in northern Asia for LGM conditions.

BIOME model run is in better agreement with the geological reconstructions (Crowley 1995, Frenzel 1992d, Grichuk 1992, Velichko and Isayeva 1992) in the Siberian region. In this area temperature is the limiting factor for vegetation growth. The coupled model here slightly overestimates the annual mean cooling in comparison with presentday values (Frenzel 1992c). Whereas increased winter time cooling better matches the geological findings this is not the case for the increased cooling during summer (e.g. Frenzel 1992a, Frenzel 1992b). The resulting temperature pattern and the subsequent shortening of the growing season lead to the discussed vegetation distribution in ECHAM-BIOME.

Remarkable temperature differences are also found in North America (see fig. 2c/d). In the north-east, temperatures in CONTROL are lower than in PLGM throughout the year. In the north-west, there are only slight differences in summer, but CONTROL yields significantly warmer winters. As these differences appear in the region of icesheets, climate can not be directly influenced by vegetation there.

Presumably, temperature differences in North America are caused by the cooling in the Siberian region in CONTROL. This cooling strengthens the meander of the jet stream determined by middle tropospheric pressure distribution (cf. fig. 4). 


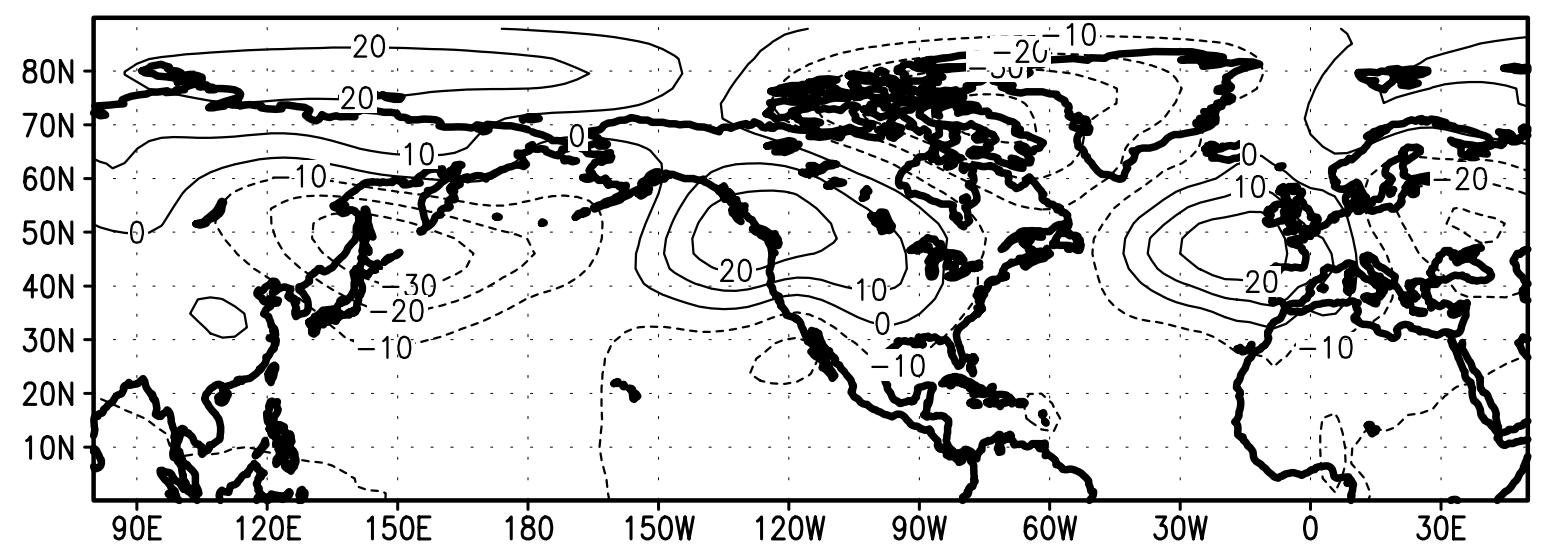

Figure 4: Difference CONTROL-PLGM of geopotential heights of the $500 \mathrm{hPa}$-surface [gpm] in East Asia, North America, and Europe (DJF).

Likewise, the change in the jet stream leads to a wetter climate in Europe in CONTROL. As a consequence, we find a further expansion of forest there which does not agree with the geological reconstructions.

Climate conditions in the southern hemisphere are determined by the surrounding oceans. There, differences between the two simulations are only small.

\subsection{Sensitivity studies}

\subsubsection{The experiments}

To explore the manifold of equilibrium solutions of the ECHAM-BIOME model under the conditions of the LGM, four additional, so-called anomaly runs have been performed. In these simulations, all land grid points are assumed to be covered by only one land surface type worldwide at the beginning of the respective simulation. The simulations have been initialized with land surface types whose surface parameters differ drastically:

FOREST - tropical rainforest (biome 1);

STEPPE - average values over all steppe and tundra biomes $(11-14)$;

DARK - hot desert (15);

BRIGHT - sand desert (18).

Again, atmospheric values have been initialized with the PLGM simulation. Up to 
seven iterations have been performed. In all cases, the last four iterations reveal no temporal trends in the areal coverage of each biome. In addition, neither the global nor the individual $\kappa$ values show any trend for this period.

The equilibrium biome distributions of individual simulations are computed from the mean climate over the trend-free iterations. In the following, equilibrium conditions of these anomaly runs and of CONTROL will be compared.

\subsubsection{Results}

The most striking differences in vegetation can be observed in North Africa (see fig. $5)$. In the simulations in which bright sand desert is prescribed at least in parts of North Africa at the beginning of the model run, i.e. in the simulations CONTROL and BRIGHT, an extended desert area is preserved. The other simulations - FOREST, STEPPE, and DARK - show an intrusion of warm grass, xerophytic woods, and savanna of up to $1,000 \mathrm{~km}$ mainly into the western Sahara, but also into the eastern Sahara and into parts of Arabia. A similar pattern is found for the Indian region. Again, CONTROL and BRIGHT reveal an extended desert area, whereas FOREST, STEPPE, and DARK show an enhanced vegetation cover.

These results suggest that there are only two solutions of the atmosphere-biosphere system under LGM boundary conditions. The existence of two equilibrium solutions is corroborated by Student t-test and $\kappa$ statistics (see table 3 ). In the following, for reasons of clarity only the simulations FOREST and BRIGHT will be discussed as representatives for the respective equilibrium group. This seems justified as there are almost no significant global or regional (North Africa and South Asia) differences in biome coverage between simulations within the equilibrium groups FOREST, STEPPE, DARK on the one hand and CONTROL, BRIGHT on the other hand.

What is the reason for the existence of the two equilibrium groups? Significant differences of climate variables are observed especially in the summer season. Following Claussen (1994), Claussen (1997a), Claussen (1997b), who obtained similar results in his simulations of present-day climate, differences in the Sahara are explained by the theory advanced by Charney (1975) and Charney et al. (1977) regarding a self-induction of deserts through albedo enhancement (cf. table 4).

As vegetated areas show a lower albedo than deserts, the surface in FOREST reflects less solar radiation than the surface in BRIGHT. At the same time, an extended cloud cover in FOREST leads to a decrease in incident solar radiation. As a result, differences 

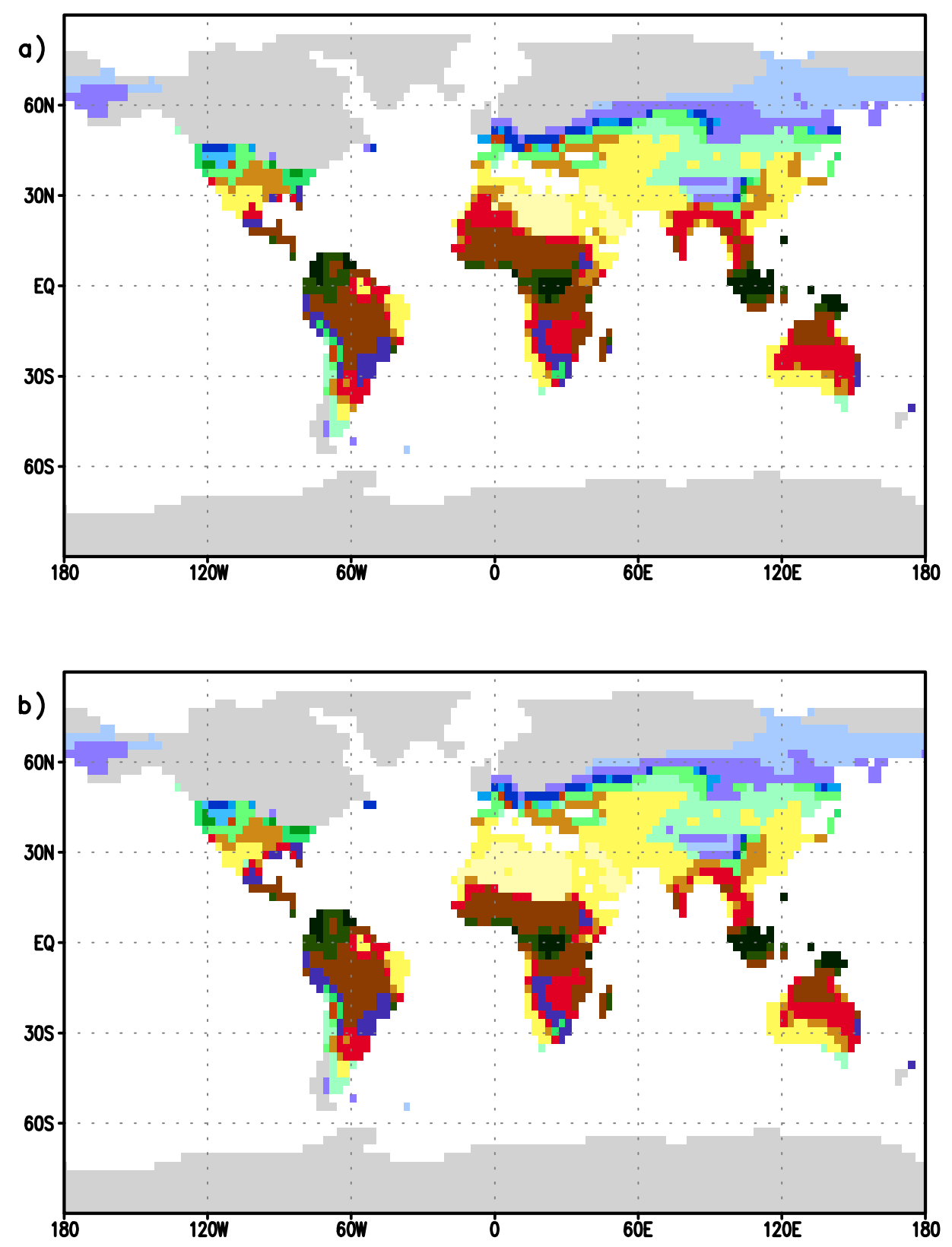

Figure 5: a) Equilibrium biome distribution of the LGM simulation FOREST with the coupled ECHAM-BIOME model when initialized with the respective anomalous biome distribution. b) Same as Figure a), but for simulation BRIGHT. The vegetation patterns of the simulations STEPPE and DARK are very similar to that of the simulation FOREST. Therefore, they are not shown here. 


\begin{tabular}{|c|c|c|c|c|c|c|c|c|c|c|}
\hline & \multicolumn{2}{|c|}{ PLGM } & \multicolumn{2}{|c|}{ CONTROL } & \multicolumn{2}{|c|}{ FOREST } & \multicolumn{2}{|c|}{ STEPPE } & \multicolumn{2}{|c|}{ DARK } \\
\hline CONTROL & 3 & 0.750 & & & & & & & & \\
\hline FOREST & 5 & 0.497 & 5 & 0.611 & & & & & & \\
\hline STEPPE & 5 & 0.504 & 5 & 0.611 & 0 & 0.965 & & & & \\
\hline DARK & 5 & 0.488 & 5 & 0.602 & 0 & 0.923 & 0 & 0.930 & & \\
\hline BRIGHT & 5 & 0.764 & 2 & 0.968 & 5 & 0.610 & 5 & 0.610 & 5 & 0.601 \\
\hline
\end{tabular}

Table 3: Differences between the LGM simulations with the atmosphere-only model ECHAM and with the coupled ECHAM-BIOME model in North Africa $\left(8-34^{\circ} \mathrm{N} / 18^{\circ} \mathrm{W}\right.$ $46^{\circ} \mathrm{E}$ ): The left-hand value gives the number of biomes (out of 5 ) whose areas differ with a significance of at least $95 \%$ between the respective simulations; the right-hand value indicates the value of $\kappa$. Note the similarity of simulations CONTROL and BRIGHT on the one hand and FOREST, STEPPE, and DARK on the other hand.

\begin{tabular}{|c|c|c|c|c|}
\hline \multirow[b]{2}{*}{ climate variable } & \multicolumn{2}{|c|}{$\begin{array}{c}\text { North Africa } \\
\left(8-34^{\circ} \mathrm{N} / 18^{\circ} \mathrm{W}-46^{\circ} \mathrm{E}\right)\end{array}$} & \multicolumn{2}{|c|}{$\begin{array}{c}\text { South Asia } \\
\left(8-31^{\circ} \mathrm{N} / 69-114^{\circ} \mathrm{E}\right)\end{array}$} \\
\hline & BRIGHT & FOREST & BRIGHT & FOREST \\
\hline vegetation ratio $[\%]$ & 28 & 46 & 45 & 56 \\
\hline background albedo [\%] & 25.5 & 21.9 & 19.1 & 18.5 \\
\hline cloud cover $[\%]$ & 36 & 42 & 45 & 49 \\
\hline shortwave radiation $\uparrow\left[\frac{W}{m^{2}}\right]$ & -73 & -59 & -44 & -43 \\
\hline shortwave radiation $\downarrow\left[\frac{W}{m^{2}}\right]$ & 297 & 281 & 289 & 284 \\
\hline net shortwave radiation $\left[\frac{\mathrm{W}}{\mathrm{m}^{2}}\right]$ & 224 & 222 & 244 & 241 \\
\hline surface temperature $\left[{ }^{\circ} \mathrm{C}\right]$ & 29,2 & 27,8 & 25.7 & 25.3 \\
\hline thermal radiation $\uparrow\left[\frac{W}{m^{2}}\right]$ & -468 & -460 & -460 & -457 \\
\hline thermal radiation $\downarrow\left[\frac{W}{m^{2}}\right]$ & 366 & 371 & 379 & 381 \\
\hline net thermal radiation $\left[\frac{W}{m^{2}}\right]$ & -102 & -89 & -81 & -76 \\
\hline net radiation $\left[\frac{W}{m^{2}}\right]$ & 122 & 133 & 164 & 166 \\
\hline sensible heat flux $\left[\frac{W}{m^{2}}\right]$ & -45 & -41 & -45 & -40 \\
\hline evaporation $\left[\frac{\mathrm{mm}}{\mathrm{mon}}\right]$ & -48 & -65 & -68 & -75 \\
\hline latent heat flux $\left[\frac{W}{m^{2}}\right]$ & -46 & -63 & -65 & -73 \\
\hline total precipitation $\left[\frac{\mathrm{mm}}{\mathrm{mon}}\right]$ & 75 & 102 & 81 & 98 \\
\hline relative soil moisture [\%] & 34 & 41 & 24 & 28 \\
\hline
\end{tabular}

Table 4: Mean values of various surface parameters and climate variables of the LGM simulations BRIGHT and FOREST with the coupled ECHAM-BIOME model (initialized with the respective anomalous biome distribution) in the regions North Africa and South Asia (JJA); negative values indicate upward fluxes. Except for the net shortwave radiation, all differences are significant at a $1 \%$ level in North Africa and at a $5 \%$ level in South Asia. 
in the net shortwave radiation between the two simulations are only small, the net longwave radiation is more important. The lower temperatures in FOREST result in a decrease in outgoing longwave radiation. More clouds lead to an enhanced atmospheric radiation. As a consequence, FOREST loses less longwave radiation than BRIGHT, leading to more available energy.

As a result of lower surface temperatures, FOREST shows a diminished sensible heat flux. The surplus energy is used for evaporation. The total energy (sensible plus latent heat) imparted to the atmosphere is increased. This leads - with the increase of the negative vertical gradient of moist static energy (Charney et al. 1976) - to enhanced convection mainly over the north-western part of the Sahara (see fig. 6a/b) and to enhanced convective precipitation in FOREST. Finally, increased precipitation in turn leads to a more widespread vegetation cover. The fact that precipitation exceeds evaporation - in FOREST more pronouced than in BRIGHT - indicates a strengthened summer monsoon which has to compensate enhanced convection.

The increased latent heat release in the middle troposphere in FOREST over the now vegetated part of the Sahara between 20 and $30^{\circ} \mathrm{N}$ results in an increase of the thickness of the atmospheric layers and thereby in enhanced divergence at $300-100 \mathrm{hPa}$. By means of the Coriolis force the tropical easterly jet (at $\sim 200 \mathrm{hPa} / 12^{\circ} \mathrm{N}$ ) as well as the westerly winds to the north are strengthened (see fig. $6 \mathrm{c} / \mathrm{d}$ ), the former extending farther over the Atlantic Ocean with higher wind speeds. Enhanced high-level convergence over the North Atlantic is clearly depicted e.g. by changes in the velocity potential (see fig. 7 ).

In addition, the African easterly jet (at $\sim 700 \mathrm{hPa} / 15^{\circ} \mathrm{N}$ ) is weakened in FOREST over North Africa (not shown here). This can be explained by the same mechanism. In BRIGHT, convection is strongest below $700 \mathrm{hPa}$, leading to the strongest divergence in the level of the African easterly jet. The higher convecting air masses over the "green" Sahara in FOREST no longer support the African but the tropical easterly jet as described above. Intensification of the tropical easterly jet during wet summers in the Sahel versus dry summers and weakening of the African easterly jet at the same time are consistent with model results of Laval and Picon (1986) and of Xue and Shukla (1993), which show good agreement with observational data.

The intensification of the tropical easterly jet is most pronounced over Africa and the Atlantic. However, some influence is noticeable east of this region, over the Indian ocean and the Indonesian archipelago (see fig. 6b/d). Consistent with enhanced convection are an increase in precipitation in FOREST, mainly to the south-west of the Himalayas, and a more extended vegetation cover in the Indian region (see table 4 and fig. 5). 

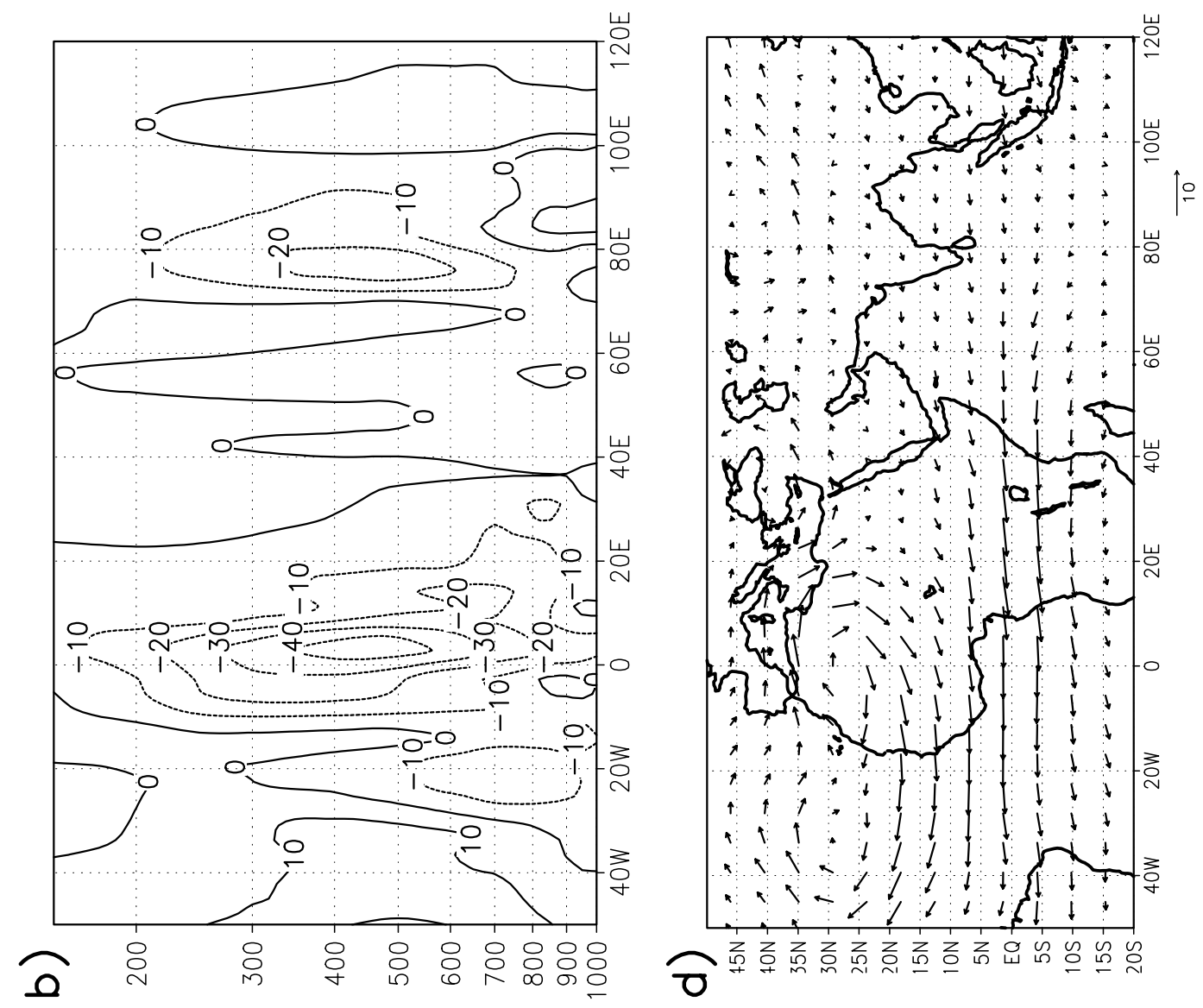

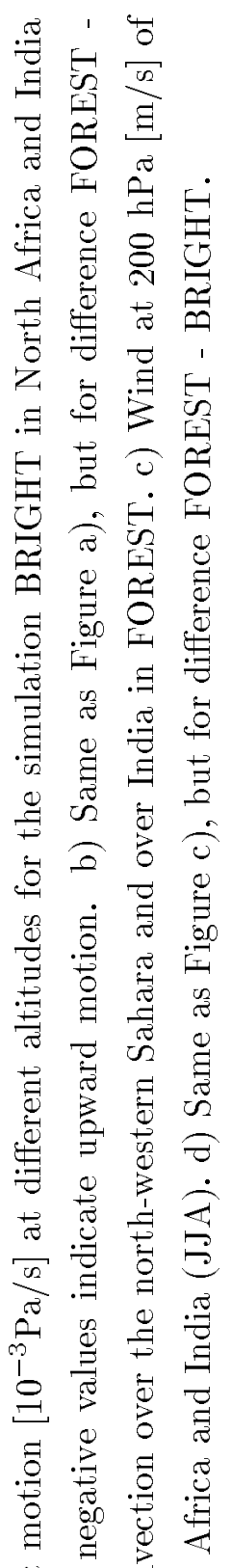

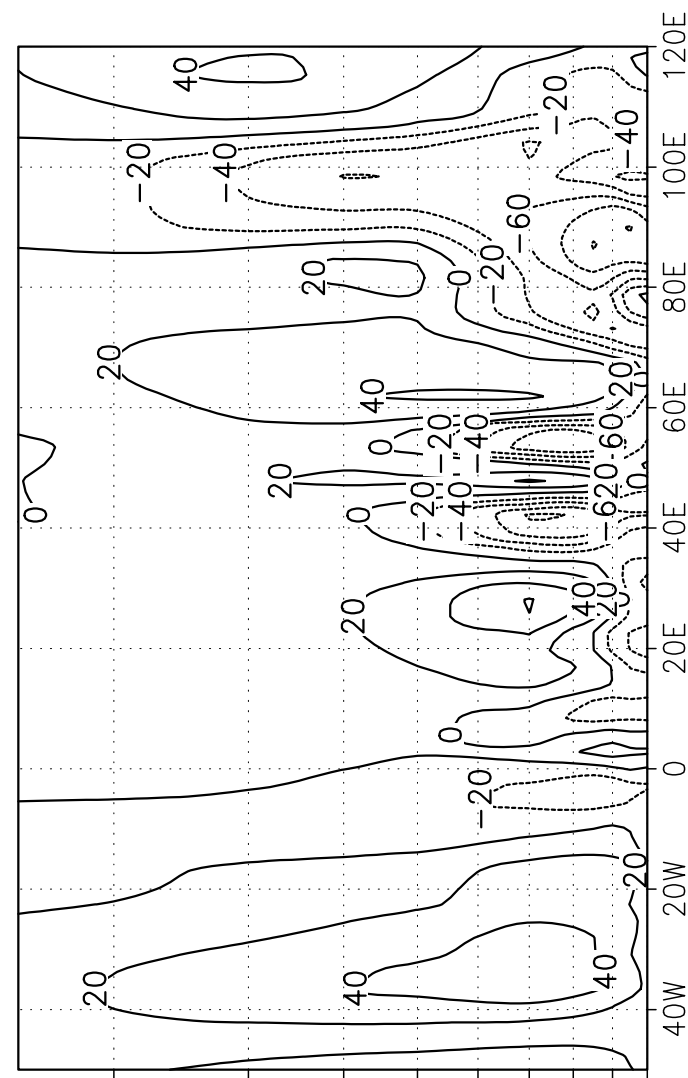

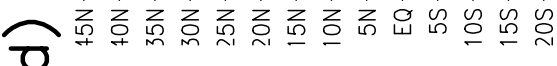

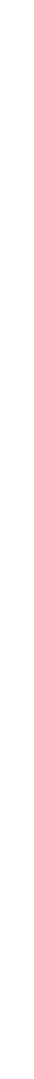

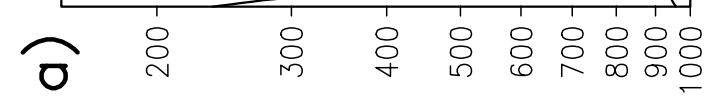

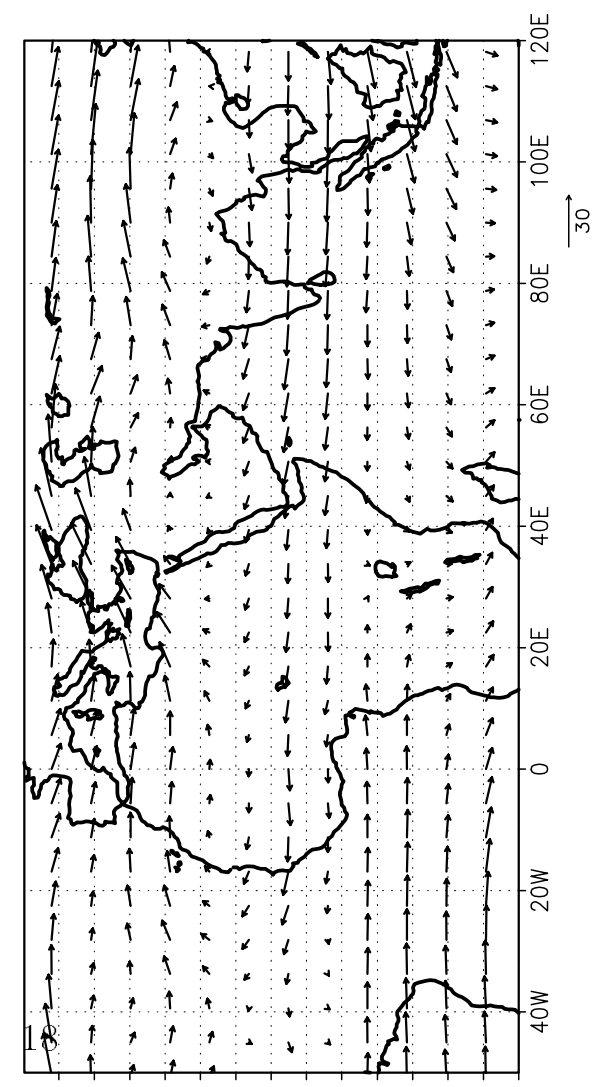

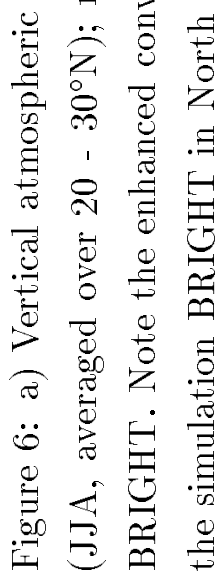

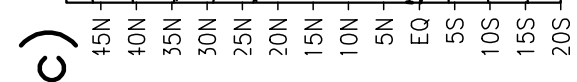



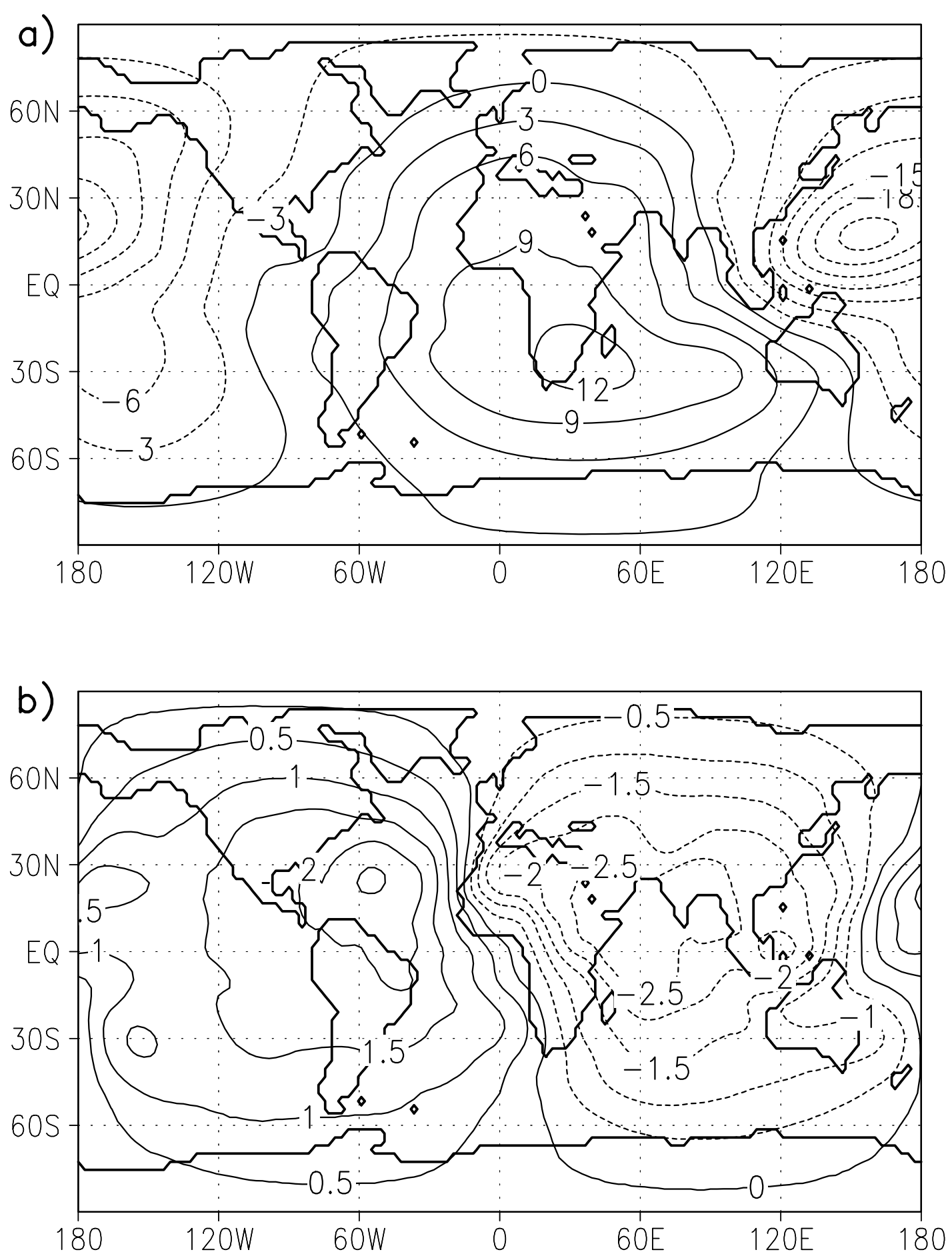

Figure 7: a) Velocity potential $\left[\mathrm{km}^{2} / \mathrm{s}\right]$ in $200 \mathrm{hPa}$ of the simulation BRIGHT (JJA). Positive values indicate convergent conditions. b) Same as Figure a), but for difference FOREST - BRIGHT. 
A positive feedback between vegetation, snow, and albedo - as described in the previous section 3.1.2 - is not found in the anomaly runs. The feedback would imply the preservation of vegetation in the simulations initialized with an extended vegetation cover. In fact, rather the opposite is observed (see fig. 5).

\section{Discussion and conclusion}

The most striking differences between the simulation with the atmosphere-only model ECHAM and the coupled ECHAM-BIOME model appear in the boreal regions of Siberia.

In the atmosphere-only model run, surface parameters representing large forest areas in that region are prescribed. The resulting climatic conditions lead to a considerable expansion of tundra, according to BIOME. With the inclusion of the vegetation-snowalbedo interaction, the coupled model yields temperatures which are up to $5^{\circ} \mathrm{C}$ lower in Siberia. As a consequence, forests are further reduced and a southward expansion of tundra and polar desert is observed. The climate in North America - and possibly also in Europe - is influenced by this cooling via a stronger meandering of the jet stream.

The sensitivity studies reveal two equilibrium states of the coupled model, depending on the initial vegetation distribution. Prescribing bright sand desert $(\alpha=35 \%)$ at the beginning of a simulation at least in parts of North Africa leads to extensive areas of desert, whereas the initial absence of sand desert (i.e. $\alpha \leq 20 \%$ ) results in a northward expansion of warm grass, xerophytic woods, and savanna of up to $1,000 \mathrm{~km}$, especially in the western Sahara.

Analysis of surface-energy budgets corroborates Charney's (1975) theory of a selfinduction of deserts through albedo enhancement. By means of enhanced convection, more widespread vegetation in the Sahara leads to an intensification of the tropical easterly jet. Consistent with stronger convection over the Indian subcontinent is an enlarged vegetation cover in that region.

Our model has been run under LGM boundary conditions - i.e. orbital parameters, SSTs, sea-ice distribution, ice sheets, orography, land-sea distribution, and $\mathrm{CO}_{2}$ concentration. In this work we focus on interactions between atmosphere and vegetation. However, as a next step the behaviour of a fully coupled atmosphere-vegetation-ocean system should be investigated. In such a system, additional feedbacks - concerning for example extend of sea-ice and monsoon circulation - can be expected (e.g. Bonan et 
al. 1992, Kutzbach and Liu 1997). Changes of the ocean circulation and thereby of the meridional heat transport should also be observed (Ganopolski et al. 1997).

In conclusion, under the given LGM boundary conditions two equilibrium solutions of ECHAM-BIOME are possible. This bifurcation is also found for present-day climate (Claussen 1994), (Claussen 1997a), (Claussen 1997b). By contrast, for the period of the Holocene Optimum only one stable solution - the "green" Sahara - is obtained (Claussen and Gayler 1997).

The question remains as to why the ECHAM-BIOME system is almost intransitive and whether this bifurcation pattern is a peculiarity of the ECHAM-BIOME model or whether it can be reproduced by other models. Further investigation should also concentrate on the question of whether the African monsoon region and the areas of boreal forests are the only regions, so to speak "hot spots", sensitive to atmosphere-vegetation feedbacks.

\section{Acknowledgements}

We thank Colin Prentice, Lund University, Sweden, for providing the BIOME model, and Stefan Lorenz, Max-Planck-Institut für Meteorologie (MPI) in Hamburg, Germany, for making the PMIP data available. Discussion with Hans-Stefan Bauer (MPI) on the tropical easterly jet is also appreciated. Thanks are due to the German Climate Computing Centre (DKRZ) in Hamburg for computing assistance. The work was undertaken while the authors were at the MPI. We also thank Alison Schlums for editing the manuscript. 
Barnola JM, Raynaud D, Korotkevich YS, Lorius C (1987) Vostok ice core provides 160,000-year record of atmospheric $\mathrm{CO}_{2}$. Nature 329: 408-414

Berger AL (1978) Long-term variations of daily insolation and Quaternary climatic changes. J Atmos Sci 35: 2362-2367

Berger AL, Loutre MF (1994) Precession, eccentricity, obliquity, insolation and paleoclimates. NATO ASI Series, Vol. I22. In: Duplessy JC, Spyridakis MT (eds) Long-Term Climatic Variations. Springer, Berlin, Heidelberg, 107-151

Bonan GB, Pollard D, Thompson SL (1992) Effects of boreal forest vegetation on global climate. Nature 359: $716-718$

Chalita S, LeTreut H (1994) The albedo of temperate and boreal forest in the Northern Hemisphere climate: A sensitivity experiment using the LMD GCM. Clim Dyn 10: $231-240$

Charney JG (1975) Dynamics of desert and drought in the Sahel. Q J R Met Soc 101: $193-202$

Charney JG, Stone PH, Quirk WJ (1976) Reply. Science 191: 100-102

Charney JG, Quirk WJ, Chow S-H, Kornfield J (1977) A comparative study of the effects of albedo change on drought in semi-arid regions. J Atmos Sci 34: 1366-1385

Claussen M (1994) On coupling global biome models with climate models. Clim Res 4: $203-221$

Claussen M (1997a) Modeling bio-geophysical feedback in the African and Indian monsoon region. Clim Dyn 13: 247-257

Claussen M (1997b) On multiple solutions of the atmosphere-vegetation system in present-day climate. Glob Change Biol, accepted

Claussen M, Gayler V (1997) The greening of Sahara during the mid-Holocene: results of an interactive atmosphere-biome model. Glob Ecol Biogeog Let, accepted 
CLIMAP Project Members (1981) Seasonal reconstruction of the earth's surface at the last glacial maximum. Geological Society of America, Map Chart Series MC-36

Crowley TJ (1995) Ice age terrestrial carbon changes revisited. Glob Biochem Cyc 9: $377-389$

Crowley TJ, North GR (1990) Paleoclimatology. Oxford Monographs on Geology and Geophysics 18, Oxford University Press, New York

de Noblet N, Prentice IC, Joussaume S, Texier D, Botta A, Haxeltine A (1996) Possible role of atmosphere-biosphere interactions in triggering the last glaciation. Geophys Res Let 23: 3191-3194

Dickinson RE, Henderson-Sellers A, Kennedy PJ, Wilson MF (1986) Biosphere - Atmosphere Transfer Scheme (BATS) for the NCAR Community Climate Model. NCAR Technical Note NCAR/TN-275+STR

Dutton JF, Barron EJ (1996) GENESIS sensitivity to changes in past vegetation. Paleoclim 1: 325-354

Foley JA, Kutzbach JE, Coe MT, Levis S (1994) Feedbacks between climate and boreal forests during the Holocene epoch. Nature 371: 52-54

Frenzel B (1992a) February mean temperature during the maximum cooling of the last glaciation. In: Frenzel B, Pecsi M, Velichko AA (eds) Atlas of Paleoclimates and Paleoenvironments of the Northern Hemisphere. Late Pleistocene - Holocene. Gustav Fischer, Stuttgart, pp 39, 97-99

Frenzel B (1992b) August mean temperature during the maximum cooling of the last glaciation. In: Frenzel B, Pecsi M, Velichko AA (eds) Atlas of Paleoclimates and Paleoenvironments of the Northern Hemisphere. Late Pleistocene - Holocene. Gustav Fischer, Stuttgart, pp 41, 97-99

Frenzel B (1992c) Annual mean temperature during the maximum cooling of the last glaciation. In: Frenzel B, Pecsi M, Velichko AA (eds) Atlas of Paleoclimates and Paleoenvironments of the Northern Hemisphere. Late Pleistocene - Holocene. Gustav Fischer, Stuttgart, pp 43, 97-99 
Frenzel B (1992d) Vegetation during the maximum cooling of the last glaciation. In: Frenzel B, Pecsi M, Velichko AA (eds) Atlas of Paleoclimates and Paleoenvironments of the Northern Hemisphere. Late Pleistocene - Holocene. Gustav Fischer, Stuttgart, pp 55, 122

Gallée H, van Ypersele JP, Fichefet T, Marsiat I, Tricot C, Berger A (1992) Simulation of the Last Glacial Cycle by a Coupled, Sectorially Averaged Climate-Ice Sheet Model: 2. Response to Insolation and $\mathrm{CO}_{2}$ Variations. J Geophys Res 97 (D14): 15713-15740

Gallimore RG, Kutzbach JE (1996) Role of orbitally induced changes in tundra area in the onset of glaciation. Nature 381: 503-505

Ganopolski A, Rahmstorf S, Petoukhov V, Claussen M (1997) Simulation of modern and glacial climates with a coupled global climate model. Nature, accepted.

Grichuk VP (1992) Main types of vegetation (ecosystems) during the maximum cooling of the last glaciation. In: Frenzel B, Pecsi M, Velichko AA (eds) Atlas of Paleoclimates and Paleoenvironments of the Northern Hemisphere. Late Pleistocene - Holocene. Gustav Fischer Verlag, Stuttgart, pp 57, 123-124

Harvey LDD (1988) On the role of high latitude ice, snow, and vegetation feedbacks in the climatic response to external forcing changes. Clim Change 13: 191-224

Jolly D, Harrison SP, Damnati B, Bonnefille R (1996) Simulated climate and biomes in Africa during the late Quaternary: Comparison with pollen and lake status data. Quat Sc Rev, in press

Joussaume S, Braçonnot P (1997) Sensitivity of paleoclimate simulation results to season definitions. J Geophys Res 102 (D2): 1943-1956

Kutzbach JE, Bonan G, Foley J, Harrison SP (1996) Vegetation and soil feedbacks on the response of the African monsoon to orbital forcing in the early to middle Holocene. Nature 384: 623-626

Kutzbach JE, Liu z (1997) Response of the African Monsoon to Orbital Forcing and Ocean Feedbacks in the Middle Holocene. Science 278: 440-443 
Laval K, Picon L (1986) Effect of a change of the surface albedo of the Sahel on climate. J Atmos Sci 43: 2418-2429

Lorenz SJ, Grieger B, Helbig P, Herterich K (1997) Investigating the sensitivity of the atmospheric general circulation model ECHAM3 to paleoclimatic boundary conditions. Geol Rundschau 85: 513-524

Monserud RA, Leemans R (1992) Comparing global vegetation maps with the Kappa statistic. Ecol Mod 62: 275-293

Otto-Bliesner BS, Upchurch GR (1997) Vegetation-induced warming of high-latitude regions during the Late Cretaceous period. Nature 385: 804-807

Prentice IC, Harrison SP, Leemans R, Monserud RA, Solomon AM (1992) A global biome model based on plant physiology and dominance, soil properties and climate. J Biogeog 19: 117-134

Roeckner E, Arpe K, Bengtsson L, Brinkop S, Dümenil L, Esch M, Kirk E, Lunkeit F, Ponater M, Rockel B, Sausen R, Schlese U, Schubert S, Windelband M (1992) Simulation of the Present-Day Climate with the ECHAM Model: Impact of Model Physics and Resolution. Rep 93, Max-Planck-Institut für Meteorologie, Hamburg

Roeckner E, Arpe K, Bengtsson L, Christoph M, Claussen M, Dümenil L, Esch M, Giorgetta M, Schlese U, Schulzweida U (1996) The atmospheric general circulation model ECHAM-4: Model description and simulation of present-day climate. Rep 218, Max-Planck-Institut für Meteorologie, Hamburg

Sellers PJ, Mintz Y, Sud YC, Dalcher A (1986) A simple biosphere model (SiB) for use within general circulation models. J Atmos Sci 43: 505-531

Stahmann M (1996) Der Einfluss unterschiedlicher Bodentypen auf die von einem globalen Atmosphaere-Biosphaere-Modell berechnete Vegetationsverteilung. Diploma Thesis, University of Hamburg, 107p

Tushingham AM, Peltier WR (1991) Ice-3G: A new global model of late pleistocene deglaciation based upon geophysical predictions of post-glacial relative sea level change. 
J Geophys Res 96 (B3): 4497-4523

Velichko AA, Isayeva LL (1992) Landscape types during the maximum cooling of the last glaciation. In: Frenzel B, Pecsi M, Velichko AA (eds) Atlas of Paleoclimates and Paleoenvironments of the Northern Hemisphere. Late Pleistocene - Holocene. Gustav Fischer Verlag, Stuttgart, pp 59, 125-126

Webb RS, Rind DH, Lehman SJ, Healy RJ, Sigman D (1997) Influence of ocean heat transport on the climate of the Last Glacial Maximum. Nature 385: 695-699

Xue Y, Shukla J (1993) The influence of land surface properties on Sahel climate. Part I: Desertification. J Clim 6: 2232-2244 